\title{
The Effect of Overweight/Obesity on Cardiovascular Responses to Acute Psychological Stress in Men Aged 50-70 Years
}

\author{
Susan J. Torres ${ }^{a} \quad$ Anne I. Turner ${ }^{a}$ Sisitha U. Jayasinghe ${ }^{a} \quad$ John Reynolds ${ }^{b}$ \\ Caryl A. Nowson ${ }^{a}$ \\ ${ }^{a}$ Centre for Physical Activity and Nutrition Research, School of Exercise and Nutrition \\ Sciences, Deakin University, Burwood, Victoria, Australia; ${ }^{b}$ Biostatistics Unit, Faculty of \\ Health, Deakin University, Burwood, Victoria, Australia
}

Key Words

Stress $\cdot$ Blood pressure $\cdot$ Obesity $\cdot$ Adults

\begin{abstract}
Background: To determine the effect of adiposity in males aged 50-70 years on cardiovascular responses to acute psychological stress. Methods: Lean (BMI $\left.20-25 \mathrm{~kg} / \mathrm{m}^{2}\right)(\mathrm{n}=21)$ and overweight/obese (BMI $\left.27-35 \mathrm{~kg} / \mathrm{m}^{2}\right)(\mathrm{n}=21)$ men aged $50-70$ years were subjected to psychological stress. Systolic blood pressure, diastolic blood pressure, heart rate, total peripheral resistance, and cardiac output were measured by a Finometer during resting (60 $\mathrm{min})$, stress (30 min), and recovery (90 min). Results: The lean group had a significantly higher SBP stress reactivity when compared to the overweight/obese group $(51.5 \pm 3.7 \%$ vs. $41.0 \pm 2.9 \%$ (mean $\pm \mathrm{SEM}) ; \mathrm{p}<0.05$ ). A significant effect of time was observed for systolic blood pressure, diastolic blood pressure, heart rate, total peripheral resistance, and cardiac output $(p<0.0001$ for all). There were significant time $\times$ body type interactions for systolic blood pressure, diastolic blood pressure, heart rate, total peripheral resistance, and cardiac output $(p<0.05$ for all). Total peripheral resistance during recovery was higher in the lean compared to the overweight/obese group $(p<0.05)$. In the lean group, systolic and diastolic blood pressure variability remained elevated after stress $(p<0.05)$ but returned to resting levels in the overweight/obese group ( $p>0.05)$. Conclusion: Moderate adiposity in men was associated with reduced systolic blood pressure \% reactivity, total peripheral resistance, and blood pressure variability after psychological stress. Overweight/obese men appear to be at no greater risk of unfavorable cardiovascular responses to stress.

(c) 2014 S. Karger GmbH, Freiburg
\end{abstract}


Torres et al.: The Effect of Overweight/Obesity on Cardiovascular Responses to Acute Psychological Stress in Men Aged 50-70 Years

\section{Introduction}

It is widely known that prolonged exposure to psychological stress contributes to the global burden of disease such as cardiovascular disease (CVD), type 2 diabetes, depression, and anxiety [1,2]. Exposure to acute psychological stressors can result in pronounced cardiovascular responses including increases in blood pressure (BP) and heart rate (HR) $[3,4]$. Hypertension is a well-established risk factor for coronary heart disease [5], and there is evidence that unfavorable cardiovascular responses during stress are risk factors for the development of hypertension. Prospective studies have found that BP responses to acute stress are associated with higher levels of resting BP measured in follow-up [6-9]. One study found that men with higher cardiovascular reactivity to acute psychological laboratory stress, involving a reaction time task at 18-22 years of age, had higher resting BP levels at 29-36 years of age [6]. In another larger study of 260 adults and their 217 children, higher BP reactivity to acute mental and physical stress challenges was associated with higher resting BP status 6.5 years later in the adults as well as the male children [7]. Furthermore, a 3-year prospective study found delayed HR and SBP recovery from psychological stress to be associated with increased resting SBP at 3-year follow-up [8].

Obesity is associated with increased risk of death, morbidity, and accelerated aging [10]. Obesity may be associated with increased cardiovascular responses to stress, which may further increase the morbidity and mortality risk among this population group. Cardiovascular responses to psychological stress has been assessed by measuring BP and HR in overweight/obese compared to lean individuals [11-14]. Overall, two studies found overweight/obese participants had higher sympathetic nervous system (SNS) responses $[11,12]$, one found lower responses in overweight/obese participants [13], and one found no significant relationship between BMI and BP or HR responses [14], but none of these studies reported the effect on cardiac output or total peripheral resistance. Furthermore, results from one animal study [15] and one human study [16] indicate that obesity is associated with an increased length of time before BP and HR return to resting levels after a stressor.

$\mathrm{BP}$ variability is being increasingly recognized as a marker and risk factor for CVD [17-20]. A meta-analysis of longitudinal studies that included more than 8,000 people found that BP variability was a significant predictor of mortality and cardiovascular and stroke events [18]. Evidence from an adolescent population indicates that BMI and waist circumference are positively associated with BP variability [20]. Collectively, this evidence may indicate that overweight/obese individuals are at greater risk of CVD by having a higher BP variability.

In summary, it is not clear if those who carry excess body weight do have a greater cardiovascular response to psychological stress, take longer to recover, or have greater BP variability in response to a stressor. Therefore, the aim of this study was to determine the effect of overweight/obesity in males aged 50-70 years on BP, HR, cardiac output (CO), total peripheral resistance (TPR), and BP variability responses and recovery to acute psychological stress compared to lean men. It was hypothesized that overweight/obese men aged 50-70 years will have a greater BP, HR, CO, TPR, and BP variability to acute psychological stress compared with lean men. 


\section{Participants and Methods}

\section{Participants}

Participants were recruited by advertisements in newspapers, workplaces, community, and health centers as well as by flyers to local residents and mail outs to participants who had participated in previous research studies. Participants were eligible for the study if they were male, 50-70 years of age, had a BMI between $20-25 \mathrm{~kg} / \mathrm{m}^{2}$ (lean group) or a BMI between $27-35 \mathrm{~kg} / \mathrm{m}^{2}$ (overweight/obese group), and a seated systolic blood pressure (SBP) of $<160 \mathrm{~mm} \mathrm{Hg}$ and diastolic blood pressure (DBP) of $<90 \mathrm{~mm} \mathrm{Hg}$. Participants were excluded from the study if they were currently taking medication to treat diabetes or were diagnosed with Cushing's syndrome, depression, stress, anxiety, adrenal gland disease, heart disease, cancer, or stroke. We excluded women from the study to overcome the difficulties of measuring stress responsiveness as sex steroids play a major role in determining stress responsiveness. For example, women in the luteal phase have higher cortisol activity to physical and psychological stress when compared to women in the follicular phase of the menstrual cycle [21].

All procedures were approved by the Human Research Ethics Committee of Deakin University (Project Code: EC 00213). All participants provided informed consent before commencing the study.

\section{Anthropometric and Screening BP Measurements}

Height to the nearest mm was measured using a stadiometer (Measurement concepts, North Bend, Australia), and weight to the nearest $0.1 \mathrm{~kg}$ was measured with the BC-418 Body Composition Analyzer (Tanita Corporation, Tokyo, Japan) with light clothing and no shoes [22]. BMI was then calculated as weight $(\mathrm{kg})$ divided by height $\left(\mathrm{m}^{2}\right)$. The BC-418 Body Composition Analyzer measured \% body fat by bioelectrical impedance. Waist circumference was measured to the nearest $\mathrm{cm}$ midway between the lowest rib margin and the iliac crest [22]. Hip circumference was measured to the nearest $\mathrm{cm}$ at the point yielding the maximum circumference over the buttocks [22]. A clinical BP monitor with a cuff size of 25-35 cm (model 506DX; Criticare Systems Inc, Waukesha, WI, USA) attached to the dominant arm was used to take BP measurements during screening, while seated, four times at 2-min intervals after the participant had rested for $5 \mathrm{~min}$. The mean of the last 3 of 4 measurements was used.

\section{Stress Procedure}

In the $12 \mathrm{~h}$ preceding the stress procedure, participants were instructed to avoid alcohol, caffeine, smoking, and vigorous exercise but were able to have their usual breakfast. The stress testing day was conducted between 11:00 am and 5:00 pm. Between 11:00 am and 12:00 pm, participants completed questionnaires and had their anthropometric measures and screening BP taken. Participants were given a standardized, low-protein lunch at $12: 00 \mathrm{pm}$. As a trial for subjects to become accustomed with the BP measurements, from 12:30 pm to $1: 30 \mathrm{pm}$, continuous beat-to-beat monitoring of BP and HR was measured by the Finometer (Finometer model-1 (PRO); Finopres Medical Systems BV, Amsterdam, the Netherlands) attached to a finger on the non-dominant arm. The average difference in SBP and DBP measured by Finometer and mercury sphygmomanometer is less than $2 \mathrm{~mm}$ $\mathrm{Hg}$; the Association for the Advancement of Medical Instrumentation requires a difference less than $5 \mathrm{~mm} \mathrm{Hg}$ mercury [23-25]. The Finometer additionally estimates systemic hemodynamic function by the Modelflow method, which provides an estimate of TPR (calculated as (mean arterial pressure / CO) $\times 80$ and expressed as dynes $\times \mathrm{s} \times \mathrm{cm}^{-5}$ ) and CO (calculated as stroke volume $\times$ instantaneous $\mathrm{HR}$ and expressed as $\mathrm{l} / \mathrm{min}$ ) [26]. While Finometer measurements give estimates rather than direct measurements of $\mathrm{CO}$ and peripheral resistance, changes over time may be observed with some precision, whereas absolute values may not [26].

Beat-to-beat monitoring of SBP, DBP, HR, CO, and TPR was undertaken from $2.00 \mathrm{pm}$ to $5.00 \mathrm{pm}$ using the Finometer. The period from 2:00 pm to 3:00 pm was defined as resting where participants remained in a seated position. From 3:00 pm to 3:30 pm the Trier Social Stress Test (TSST) was imposed (stress) and consisted of a 10-min anticipatory period, followed by a 5-min public speaking task and a 5-min mental arithmetic task performed in front of an audience of two individuals with subjects standing, which was filmed and voice recorded [27]. After the conclusion of the stressor, the participants were required to rest in a seated position from 3:30 pm to 5:00 pm (recovery). 
Torres et al.: The Effect of Overweight/Obesity on Cardiovascular Responses to Acute Psychological Stress in Men Aged 50-70 Years

\section{Data Analyses}

\section{Preliminary Analyses}

Data were calculated as means of 2-min blocks every $10 \mathrm{~min}$ for SBP, DBP, HR, CO, and TPR resulting in 90 time points for each variable. The definitions for the different phases were: resting (60 $\mathrm{min})-6$ data points; stress (30 $\mathrm{min}$ ) - 15 data points; recovery ( $90 \mathrm{~min}$ ) - 9 data points. Peak stress was the highest point reached during the stress period, and stress reactivity was the difference between peak stress and average resting values. Percentage stress reactivity was calculated using the equation (stress reactivity / average resting) $\times 100$. Recovery time over $90 \mathrm{~min}$ was calculated as time taken to return within 2 standard deviations (SDs) of average resting values. BP variability was computed from the SD of all BP readings during resting (approximately 3,820 data points), stress (approximately 2,150 data points), and recovery (approximately 5,610 data points).

\section{Analysis}

Data were analyzed using SPSS 22.0 for Windows (SPSS Inc., Chicago, IL, USA) and GenStat statistical package (Release 14.2). All data are reported as means \pm their standard errors (SEMs) unless otherwise indicated. All data were normally distributed as assessed by skewness and kurtosis statistics. Comparisons of the groups for the cardiovascular indices were determined using independent-sample t-tests. A one-way repeated measures ANOVA was conducted to compare the BP variability across the three phases for each group.

For each cardiovascular parameter, a repeated measures analysis of variance was performed, and the standard assumptions (homogeneity of variance and an equi-correlation structure for evaluations within subjects) were checked via diagnostic plots and inspection of the within-subject correlation matrix. If required, a log transformation was used to ensure homogeneity of variance, and the Greenhouse-Geisser epsilon adjustment to the degrees of freedom in the F-tests was used in the calculation of the $p$ values for the tests of the time main effect and the time by group interaction. In further analyses, via restricted maximum likelihood (REML), five standard variance-covariance models for the within-subject assessments (identity matrix, diagonal matrix, 1st order moving average, 1st order autoregressive and 1st order autoregressive moving-average) were explored and the model with the smallest value of the Akaike Information Criterion (AIC) was identified. F-tests were reported for the selected linear mixed model and in a further set of analyses, additional models, with time fitted as a continuous covariate, were explored. F-tests for different linear trends between the groups of subjects were conducted, and cubic smoothing splines were fitted to investigate the nonlinear time trends in the data. The AIC was also used to ascertain if a common spline adequately represented departures of subjects' time profiles from linearity or if separate splines were required for each group of subjects. In all analyses, $\mathrm{p}<0.05$ was considered statistically significant.

We estimated that 40 subjects in total (20 lean and 20 overweight/obese) were needed to detect a $6 \mathrm{~mm}$ Hg difference between groups in absolute levels of SBP during stress with a significance level of 0.05 and a power of $80 \%$.

\section{Results}

\section{Subject Characteristics}

Of the 56 participants who attended screening, 48 were eligible and were invited to participate in the study. 47 participants completed the study; one subject declined to take part in the TSST and withdrew. Due to technical difficulties with the Finometer BP monitor during the study, data were excluded for 5 participants. 42 participants were included in the final analysis: 21 were in the lean group, and 21 were in the overweight/obese group.

The baseline characteristics of the participants are summarized in table 1 . The lean group was 3.8 years older $(p<0.05)$ than the overweight/obese group and had a significantly lower weight, BMI, waist circumference, hip circumference, and \% body fat. The mean BMI for the lean group fell within the healthy range $\left(18.5-24.9 \mathrm{~kg} / \mathrm{m}^{2}\right)$, whereas the mean BMI for the overweight/obese group fell within the grade 1 obese range ( 30 to $<35 \mathrm{~kg} / \mathrm{m}^{2}$ ) [28]. The lean 


\begin{tabular}{|c|c|c|c|}
\hline \multicolumn{4}{|l|}{ Obes Facts 2014;7:339-350 } \\
\hline \multicolumn{2}{|l|}{ DOI: 10.1159/000369854 } & \multicolumn{2}{|c|}{$\begin{array}{l}\text { (c) } 2014 \text { S. Karger GmbH, Freiburg } \\
\text { www.karger.com/ofa }\end{array}$} \\
\hline \multicolumn{4}{|c|}{$\begin{array}{l}\text { Torres et al.: The Effect of Overweight/Obesity on Cardiovascular Responses to Acute } \\
\text { Psychological Stress in Men Aged 50-70 Years }\end{array}$} \\
\hline Characteristic & $\begin{array}{l}\text { Lean } \\
(n=21)\end{array}$ & $\begin{array}{l}\text { Overweight/obese } \\
(n=21)\end{array}$ & p value \\
\hline Age, years & $64.3 \pm 5.0$ & $60.5 \pm 4.9$ & 0.019 \\
\hline Weight, kg & $70.6 \pm 6.9$ & $94.7 \pm 9.0$ & $<0.001$ \\
\hline $\mathrm{BMI}, \mathrm{kg} / \mathrm{m}^{2}$ & $23.4 \pm 1.2$ & $31.1 \pm 2.3$ & $<0.001$ \\
\hline BMI range, $\mathrm{kg} / \mathrm{m}^{2}$ & $20.5-24.9$ & $27.2-34.3$ & NA \\
\hline Waist circumference, $\mathrm{cm}$ & $86.3 \pm 1.5$ & $108.5 \pm 6.5$ & $<0.001$ \\
\hline Hip circumference, $\mathrm{cm}$ & $98.6 \pm 5.5$ & $110.3 \pm 5.6$ & $<0.001$ \\
\hline$\%$ Body fat & $20.0 \pm 4.6$ & $29.3 \pm 4.3$ & $<0.001$ \\
\hline $\mathrm{SBP}, \mathrm{mm} \mathrm{Hg}$ & $119.1 \pm 13.4$ & $127.7 \pm 10.6$ & $<0.05$ \\
\hline DBP, $\mathrm{mm} \mathrm{Hg}^{\mathrm{C}}$ & $67.0 \pm 8.6$ & $75.1 \pm 7.7$ & $<0.05$ \\
\hline $\mathrm{HR}$, beats $/ \min ^{\mathrm{C}}$ & $64.2 \pm 12.2$ & $64.7 \pm 9.9$ & 0.867 \\
\hline 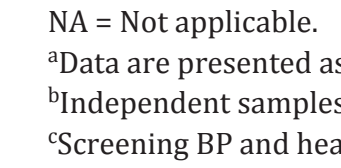 & $\begin{array}{l}\text { means } \pm \text { SD. } \\
\text { t-test, } p<0.05 \\
\text { t rate. }\end{array}$ & & \\
\hline
\end{tabular}

Table 1. Characteristics of men in the lean and overweight/ obese groups $^{\mathrm{a}}$

group also had a waist circumference within the healthy range $(\leq 94 \mathrm{~cm})$, while the overweight/obese group had a waist circumference greater than the healthy range $(>94 \mathrm{~cm})[29]$. Screening SBP and DBP was significantly higher in the overweight/obese group when compared to the lean group. There were no significant differences in age, screening SBP, DBP, HR, or BMI between participants who completed the study $(n=42)$ and those who dropped out or were excluded from the final analysis ( $\mathrm{n}=14$; data not shown).

\section{Effect of Body Type on Cardiovascular Indices during the Stress Procedure}

For all of the cardiovascular response measures there was evidence of departure from the equi-correlation assumption, and in all cases the REML analyses indicated that the 1 st order autoregressive moving average model, ARMA(1,1), was the best-fitting model of the five contemplated models for the variance-covariance structure. Accordingly, we only present results from the REML analyses which utilized the ARMA $(1,1)$ model.

When time was analyzed as a continuous covariate and potentially different departures from linearity were investigated, in each case a common spline gave the best fit (smallest AIC) compared to separate splines for the lean and overweight/obese groups.

\section{$S B P$}

There was no significant overall difference between the groups $(p=0.287)$, but there was a significant time effect $(\mathrm{p}<0.001)$ and a significant group by time interaction $(\mathrm{p}=0.018$; fig. 1a). However, pairwise comparisons revealed no significant differences between the two groups at any of the 90 time points.

When time was regarded as a continuous covariate, there was a significant linear increase in SBP with time in the lean group $(\beta=0.243 \pm 0.049)$, and the slope in the overweight/obese group was not significantly different $(p=0.895)$ from the slope in the lean group. There was no difference between the groups in their deviations from the linear trend, and both groups had peaks during stress at 3:08 pm, 3:22 pm and 3:28 pm and troughs at 3:16 pm and 3:26 pm (fig. 1a). 
Torres et al:: The Effect of Overweight/Obesity on Cardiovascular Responses to Acute Psychological Stress in Men Aged 50-70 Years

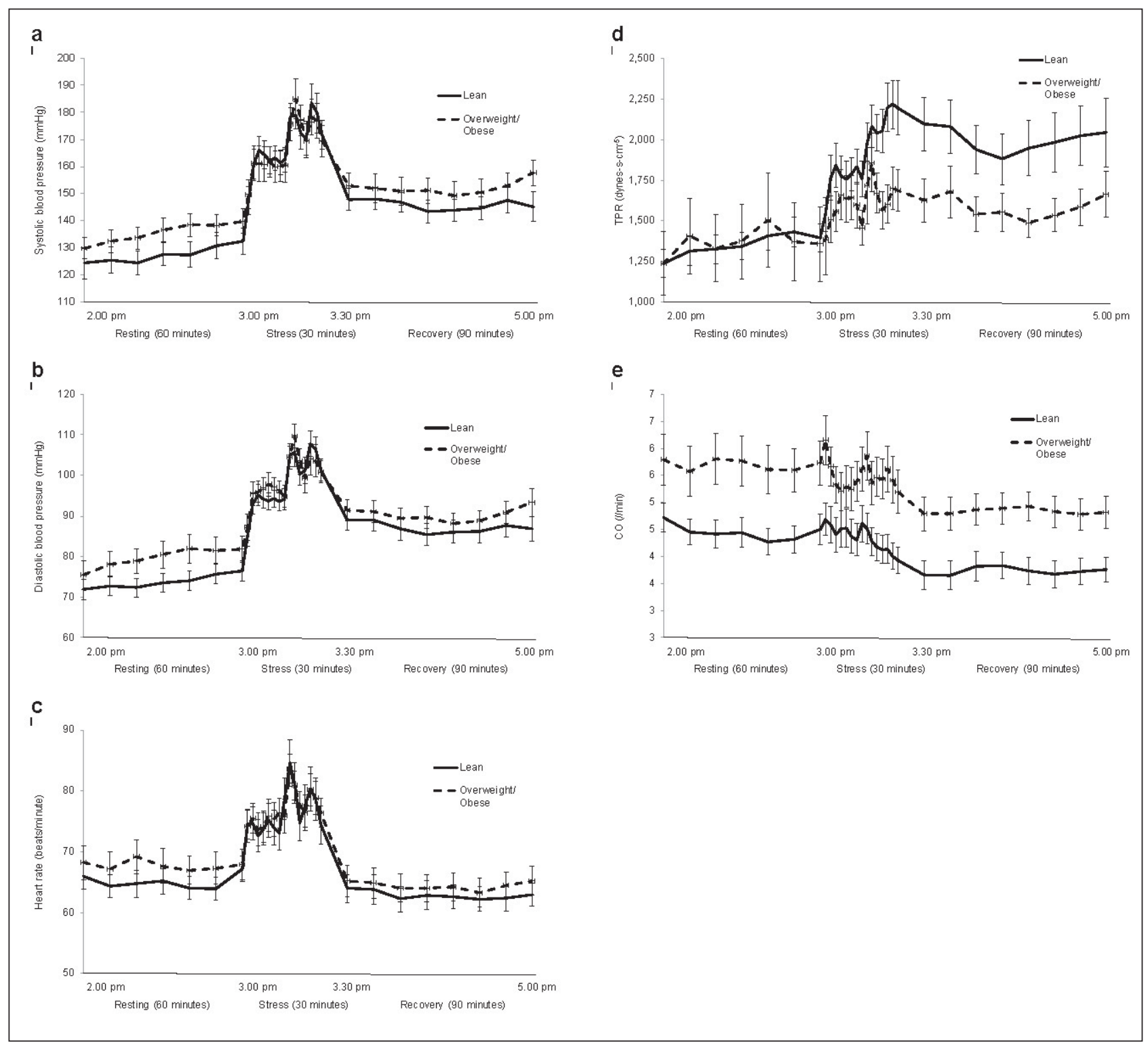

Fig. 1. Cardiovascular responses during resting, stress, and recovery. All data are mean \pm SEM a SBP, $\mathbf{b} D B P$, c HR, $\mathbf{d}$ TPR and e CO during the 3-hour testing period. A repeated measures split-plot-in-time analysis of variance was used in the statistical analysis. SBP: time effect, $p<0.001$; time $\times$ body type interaction, $p=$ 0.018 ; body type effect, $\mathrm{p}=0.287$. DBP: time effect, $\mathrm{p}<0.001$; time $\times$ body type interaction, $\mathrm{p}<001$; body type effect, $p=0.194$. HR: time effect, $p<0.001$; time $\times$ body type interaction, $p=0.033$; body type effect, $p=$ 0.579. TPR: time effect, $p<0.001$; time $\times$ body type interaction, $p=0.039$; body type effect, $p=0.101$. CO: time effect, $\mathrm{p}<0.001$; time $\times$ body type interaction, $\mathrm{p}=0.025$; body type effect, $\mathrm{p}=0.009$.

SBP stress reactivity was $10 \%$ higher in the lean when compared to the overweight/ obese group ( $p<0.05$; table 2). There were no differences between the groups in SBP during all phases as well as with regard to recovery time ( $p>0.05$ for all).

$D B P$

There was no significant overall difference between the groups $(p=0.194)$, but there was a significant time effect $(\mathrm{p}<0.001)$ and a significant group by time interaction $(\mathrm{p}<0.001$; 
Torres et al.: The Effect of Overweight/Obesity on Cardiovascular Responses to Acute Psychological Stress in Men Aged 50-70 Years

Table 2. Cardiovascular indices of men in the lean and overweight/obese groups ${ }^{\mathrm{a}}$

\begin{tabular}{|c|c|c|c|}
\hline Cardiovascular parameter & $\begin{array}{l}\text { Lean } \\
(n=21)\end{array}$ & $\begin{array}{l}\text { Overweight/obese } \\
(n=21)\end{array}$ & $p$ value ${ }^{b}$ \\
\hline \multicolumn{4}{|l|}{ Resting } \\
\hline $\mathrm{SBP}, \mathrm{mm} \mathrm{Hg}$ & $127.1 \pm 4.0$ & $136.3 \pm 4.5$ & 0.138 \\
\hline DBP, mm Hg & $73.7 \pm 2.3$ & $80.2 \pm 3.1$ & 0.103 \\
\hline $\mathrm{HR}$, beats/min & $65.0 \pm 1.9$ & $67.7 \pm 2.6$ & 0.408 \\
\hline TPR, dynes $\times \mathrm{s} \times \mathrm{cm}^{-5}$ & $1,361.4 \pm 83.3$ & $1,384.4 \pm 227.4$ & 0.925 \\
\hline $\mathrm{CO}, \mathrm{l} / \mathrm{min}$ & $4.4 \pm 0.2$ & $5.7 \pm 0.4$ & 0.017 \\
\hline \multicolumn{4}{|l|}{ Stress peak } \\
\hline $\mathrm{SBP}, \mathrm{mm} \mathrm{Hg}$ & $192.0 \pm 6.7$ & $190.5 \pm 4.8$ & 0.859 \\
\hline DBP, mm Hg & $111.5 \pm 2.8$ & $113.2 \pm 2.9$ & 0.670 \\
\hline $\mathrm{HR}$, beats/min & $87.4 \pm 3.2$ & $85.5 \pm 2.6$ & 0.642 \\
\hline TPR, dynes $\times \mathrm{s} \times \mathrm{cm}^{-5}$ & $2,351.0 \pm 135.6$ & $2,308.8 \pm 285.6$ & 0.894 \\
\hline $\mathrm{CO}, \mathrm{l} / \mathrm{min}$ & $5.2 \pm 0.3$ & $6.7 \pm 0.4$ & 0.010 \\
\hline \multicolumn{4}{|l|}{ Stress reactivity, \% } \\
\hline SBP & $51.5 \pm 3.7$ & $41.0 \pm 2.9$ & 0.032 \\
\hline DBP & $52.7 \pm 4.2$ & $35.1 \pm 3.8$ & 0.131 \\
\hline HR & $35.1 \pm 3.8$ & $28.3 \pm 4.3$ & 0.243 \\
\hline TPR & $76.1 \pm 7.1$ & $94.5 \pm 27.8$ & 0.526 \\
\hline $\mathrm{CO}$ & $0.8 \pm 0.2$ & $1.0 \pm 0.3$ & 0.383 \\
\hline \multicolumn{4}{|l|}{ Recovery } \\
\hline $\mathrm{SBP}, \mathrm{mm} \mathrm{Hg}$ & $146.6 \pm 4.7$ & $152.8 \pm 3.9$ & 0.324 \\
\hline DBP, mm Hg & $87.3 \pm 2.6$ & $90.8 \pm 2.4$ & 0.331 \\
\hline $\mathrm{HR}$, beats/min & $63.3 \pm 2.1$ & $64.9 \pm 2.3$ & 0.615 \\
\hline TPR, dynes $\times \mathrm{s} \times \mathrm{cm}^{-5}$ & $1,972.9 \pm 152.9$ & $1,586.1 \pm 110.7$ & 0.047 \\
\hline $\mathrm{CO}, \mathrm{l} / \mathrm{min}$ & $3.8 \pm 0.2$ & $4.8 \pm 0.3$ & 0.007 \\
\hline \multicolumn{4}{|l|}{ Recovery time, min } \\
\hline SBP & $43.4 \pm 8.1$ & $34.7 \pm 7.0$ & 0.423 \\
\hline DBP & $46.9 \pm 8.0$ & $47.1 \pm 8.1$ & 0.980 \\
\hline HR & $6.8 \pm 1.5$ & $5.0 \pm 0.4$ & 0.275 \\
\hline TPR & $54.1 \pm 8.6$ & $49.1 \pm 9.0$ & 0.687 \\
\hline $\mathrm{CO}$ & $2.7 \pm 0.3$ & $7.9 \pm 4.2$ & 0.227 \\
\hline
\end{tabular}

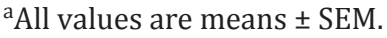

bIndependent samples t-test, $\mathrm{p}<0.05$.

fig. 1b). Pairwise comparisons revealed two times during resting, 2:40 pm and 2:46 pm, where DBP was higher in the overweight/obese group.

When time was regarded as a continuous covariate, there was a significant linear increase in DBP with time in the lean group $(\beta=0.175 \pm 0.040)$ which did not differ from the slope in the overweight/obese group ( $p=0.828)$. There was no difference between the groups in their deviations from the linear trend and peaks during stress at 3:06 pm, 3:20 pm and 3:26 pm and troughs at 3:16 pm and 3:24 pm (fig. 1b).

There were no differences between the groups in DBP during resting, stress, or recovery as well as with regard to recovery time ( $p>0.05$ for all; table 2 ).

$H R$

There was no significant overall difference between the groups $(\mathrm{p}=0.579)$, but there was a significant time effect $(\mathrm{p}<0.001)$ and a significant group by time interaction $(\mathrm{p}=0.033$; 
fig. 1c). However, pairwise comparisons revealed no significant difference at any of the time points.

When time was regarded as a continuous covariate there was a significant linear decrease in HR with time in the lean group $(\beta=-0.057 \pm 0.012)$, and this did not differ from the slope in the overweight/obese group ( $\mathrm{p}=0.345)$. There was no difference between the groups in their deviations from the linear trend with peaks during stress at 3:04 pm, 3:18 pm and 3:26 pm and troughs at 3:14 pm and 3:22 pm (fig. 1c).

There were no differences between the groups in HR during resting, stress or recovery as well as with regard to recovery time ( $p>0.05$ for all; table 2$)$.

\section{$T P R$}

To ensure homogeneity of variance, TPR was log transformed. There was no significant overall difference between the groups $(\mathrm{p}=0.101)$, but there was a significant time effect $(\mathrm{p}<$ 0.001 ) and a significant group by time interaction ( $p=0.039$; fig. $1 \mathrm{~d})$. TPR was significantly higher in the lean group during stress and recovery; pairwise comparisons revealed 15 time points (3:24 pm, 3:26 pm, 3:28 pm, 3:30 pm, 3:34 pm, 3:40 pm, 3:42 pm, 3:44 pm, 3:48 pm, 3:52 pm, 3:54 pm, 3:56 pm, 4:20 pm, 4:22 pm, and 4:44 pm).

There was a significant linear increase in TPR with time in the lean group ( $\beta=0.002 \pm$ $0.000)$, and this did not differ from the slope in the overweight/obese group ( $p=0.526)$. There was no difference between the groups in their deviations from the linear trend, and both groups had peaks during stress at 3:06 pm, 3:20 pm and 3:28 pm and troughs at 3:16 pm and 3:24 pm (fig. 1d).

TPR during recovery was higher in the lean group than in the overweight/obese group ( $p<0.05$; table 2). There were no differences between the groups in TPR during resting and stress as well as with regard to recovery time ( $p>0.05$ for all; table 2).

Further analysis of TPR which included baseline $\mathrm{CO}$ as a covariate did not change the findings for TPR (data not shown).

CO

There was a significant overall difference between the groups $(p=0.009)$, a significant time effect $(\mathrm{p}<0.001)$, and a significant group by time interaction $(\mathrm{p}=0.025$; fig. 1 e). Pairwise comparisons revealed significant differences between the groups at all time points except for times 3:10 pm to 3:14 pm (stress) and 4:06 pm (recovery) (higher CO in the overweight/ obese group).

There was a significant linear decrease in CO with time in both groups $(\beta=-0.012 \pm$ $0.004)$ and the linear slope did not differ from in the overweight/obese group $(p=0.631)$. There was no difference between the groups in their deviations from the linear trend, and both groups had peaks during stress at 3:02 pm, 3:18 pm and 3:20 pm and troughs at 3:12 pm and 3:20 pm (fig. 1e).

CO during resting, at stress peak and during recovery was significantly lower in the lean group than in the overweight/obese group ( $p<0.05$; table 2 ). There was no difference in recovery time between the groups $(p>0.05)$.

\section{BP Variability during Resting, Stress, and Recovery}

There were no significant differences between the groups in SBP and DBP variability during resting, stress, or recovery (table 3 ). For the lean group, there was a significant effect of time for SBP and DBP variability ( $\mathrm{p}<0.0001$ for both). Post-hoc tests revealed a significant difference between all time points for SBP and DBP variability ( $p<0.0001$ for all). This indi- 


\begin{tabular}{|c|c|c|c|}
\hline \multicolumn{4}{|l|}{ Obes Facts $2014 ; 7: 339-350$} \\
\hline \multicolumn{2}{|l|}{ DOI: 10.1159/000369854 } & \multicolumn{2}{|c|}{$\begin{array}{l}\text { (c) } 2014 \text { S. Karger GmbH, Freiburg } \\
\text { www.karger.com/ofa }\end{array}$} \\
\hline \multicolumn{4}{|c|}{$\begin{array}{l}\text { Torres et al.: The Effect of Overweight/Obesity on Cardiovascular Responses to Acute } \\
\text { Psychological Stress in Men Aged 50-70 Years }\end{array}$} \\
\hline Cardiovascular parameter & $\begin{array}{l}\text { Lean } \\
(n=21)\end{array}$ & $\begin{array}{l}\text { Overweight/obese } \\
(\mathrm{n}=21)\end{array}$ & p value ${ }^{b}$ \\
\hline \multicolumn{4}{|l|}{ Resting } \\
\hline SBP SD, mm Hg & $5.3 \pm 0.5$ & $6.8 \pm 1.1$ & 0.249 \\
\hline DBP SD, mm Hg & $3.2 \pm 0.3$ & $4.2 \pm 0.8$ & 0.237 \\
\hline \multicolumn{4}{|l|}{ Stress } \\
\hline SBP SD, mm Hg & $17.5 \pm 1.4$ & $16.4 \pm 1.2$ & 0.541 \\
\hline DBP SD, mm Hg & $9.9 \pm 0.6$ & $10.0 \pm 0.9$ & 0.913 \\
\hline \multicolumn{4}{|l|}{ Recovery } \\
\hline SBP SD, mm Hg & $9.6 \pm 1.2$ & $7.3 \pm 0.6$ & 0.098 \\
\hline DBP SD, mm Hg & $5.5 \pm 0.7$ & $4.3 \pm 0.4$ & 0.151 \\
\hline $\begin{array}{l}\mathrm{SD}={ }^{\mathrm{a}} \text { All values are mea } \\
{ }^{\mathrm{b}} \text { Independent samples } \mathrm{t}\end{array}$ & $\begin{array}{l}\text { IS } \pm \text { SEM. } \\
\text { test, } p<0.05\end{array}$ & & \\
\hline
\end{tabular}

Table 3. BP variability of men in the lean and overweight/obese groups $^{\mathrm{a}}$

cated that SBP and DBP variability significantly increased during the stress period, then significantly decreased after the stressor ceased. However, SBP and DBP variability remained above resting values during recovery. For the overweight/obese group, there was also a significant effect of time for SBP and DBP variability ( $p<0.0001$ for both). Post-hoc tests revealed that there was a significant increase in SBP and DBP variability during stress and then a significant decrease after the stressor ceased ( $p<0.0001$ for all). There was no difference in SBP and DBP variability between resting and recovery ( $p>0.05$ for all), indicating that SBP and DBP variability returned to resting levels after the stressor ceased in this group.

\section{Discussion}

We found in a sample of men with excess body weight that they had a $10 \%$ lower rise in SBP in response to acute psychological stress and lower TPR levels during recovery when compared to lean men. BP variability increased in both groups in response to the stressor, but in the overweight/obese men BP variability returned to resting levels, but remained elevated in lean men. These responses suggest that overweight/obese have an attenuated SBP response to psychological stress with reduced BP variability. These findings are contrary to previous studies indicating that obesity is associated with increased physiological responses to stress. These findings could, however, indicate that increased body weight is associated with reduced cardiovascular physiological responses to a stressor [30,31]. Since the absolute peak height of the response was similar in both groups, it could be that there is a ceiling effect preventing increases in BP to extremely high dangerous levels.

In contrast to our finding that the lean group compared to the overweight/obese group had a greater SBP reactivity, two studies found greater BP reactivity among overweight/ obese adolescents [12] and adults [11]. However, the study conducted in adolescents had a family history of hypertension [12]. As increased BP during laboratory stress tests have been found to be a measure of future hypertension risk [9], there may be a genetic basis for increased responses during stress, and thus the results may not be generalizable to a healthy population or comparable to an adult population. A limitation of the study in adults was that the mean BMI in the lower BMI group still fell within the overweight range [11]. There was, however, a large BMI difference between groups with the upper BMI group falling within the 
Torres et al.: The Effect of Overweight/Obesity on Cardiovascular Responses to Acute Psychological Stress in Men Aged 50-70 Years

obese category. Another study found that plasma epinephrine responses to mental stress were lower in lean borderline hypertensive men when compared to overweight borderline hypertensive men [13]. Two studies found no association between BMI and cardiovascular stress responses [14,32]. We demonstrated that the lean and overweight/obese had a similar $\mathrm{BP}$ variability at resting, and BP variability returned to resting levels after cessation of the stressor in the overweight/obese men but remained elevated in the lean group. It would appear that overweight and obese men are at no greater risk of CVD due to an elevation in BP reactivity.

Previously, we reported that weight loss of $5 \%$ facilitated a faster recovery of SBP to resting levels after stress [33]. However, in the present study, we found no difference between the groups in recovery time for any of the cardiovascular measures. Our results conflict with those of Steptoe and Wardle [32] who found that a higher BMI was associated with impaired $\mathrm{BP}$ and $\mathrm{CO}$ recovery in response to mental stress in a 3-year longitudinal study in a sample of 225 healthy men and women. In the present study, SBP and DBP decreased during the recovery period, but remained above resting levels even after $90 \mathrm{~min}$ in both groups. In contrast, $\mathrm{HR}$ and $\mathrm{CO}$ were lower during the resting phase. TPR also remained above resting levels during the recovery period indicating that the elevated BP was being sustained by the raised TPR. This pattern of cardiovascular responses during rest, stress, and recovery is consistent with two studies published by Steptoe et al. [34] and Steptoe and Marmot [35]. Furthermore, it has also been proposed that raised TPR in response to stress is related to increased CVD risk [34]; our findings suggest that this may be more relevant to the lean than to the overweight/obese group. However, resting SBP for both groups was within the prehypertension range [36], although there was no significant difference in resting SBP between the groups, but screening BP was higher in the overweight/obese group compared to the lean group. It is unclear why there was a difference in screening BP between the groups and no difference in resting BP during the stress procedure. It is possible that the extended time period during resting $(1 \mathrm{~h})$ masked any differences between the groups.

Baseline CO was significantly higher in overweight/obese compared to lean men. This reflects differences in cardiovascular regulation between lean and obese individuals [37]. Furthermore, it is known that both CO and TPR contribute to CVD risk [38]. Nevertheless, inclusion of baseline $\mathrm{CO}$ as a covariate in the analysis of TPR did not affect the findings.

Major strengths of this study are a reliable stressor, non-invasive continuous measurements of cardiovascular variables, and long resting and recovery periods. This study used the TSST as the stressor, which consists of several components (public speaking, mental arithmetic, audience, and an anticipatory period) and has been found to elicit larger and more consistent increases in BP and HR than protocols employing only one type of stressor [39]. The TSST elicited substantially greater cardiovascular responses during stress than has been found in other studies in this area. In the present study, there was an increase in SBP of 34 $\mathrm{mm} \mathrm{Hg}$, while Steptoe and Wardle [32] reported a SBP increase of only $22 \mathrm{~mm} \mathrm{Hg}$ using two behavioral tasks: a computerized color-word interference task and mirror tracing. The use of the Finopres BP monitor for the duration of the study was an advantage as small cardiovascular changes could be detected as they took place on a beat to beat basis [24]. Furthermore, the Finopres technology has been validated in cardiovascular research [40, 41]. The 60-min resting period, which was preceded by a 3-hour adaptation period, ensured that BP and HR were at resting levels before commencement of the stress test. Some previous studies had much shorter resting periods. Waldstein et al. [11] had a resting period of only $10 \mathrm{~min}$, Barnes et al. [12] had a 15-min resting period, Reims et al. [13] had a 20-min resting period, and Steptoe and Wardle [32] used a 30-min resting period; therefore, participants may not have reached resting levels before commencement of stress. A limitation of this study was the selfreferral method of recruitment which may mean that the population is not representative of 
Torres et al:: The Effect of Overweight/Obesity on Cardiovascular Responses to Acute Psychological Stress in Men Aged 50-70 Years

the Australian population of men aged 50-70 years. The findings from the present study could have been strengthened by measures of self-reported stress. Another potential limitation is that the overweight/obese group was 4 years younger than the lean group, so it is possible the favorable responses to stress in the overweight/obese group may be due to this age difference.

Overweight/obese compared to lean men had lower SBP reactivity to stress, lower TPR levels during recovery and lower BP variability levels which returned to resting levels. It would appear that, with respect to these indices, overweight/obese men are at no greater risk of unfavorable cardiovascular responses to stress. However, the possibility remains that men with more extreme levels of obesity, including morbid obesity, will have unfavorable cardiovascular responses to stress.

\section{Acknowledgements}

The authors acknowledge Emma Townsin and Maryam Delavari for their assistance in conducting the stress tests.

\section{Disclosure Statement}

The authors declare no conflict of interest.

\section{References}

1 World Health Organisation: The World Health Report 2001. Mental Health: New Understanding, New Hope. Geneva, WHO, 2001.

-2 Chrousos GP: Stress and disorders of the stress system. Nat Rev Endocrinol 2009;5:374-381.

-3 Folkow B: Physiological aspects of the 'defence' and 'defeat' reactions. Acta Physiol Scand Suppl 1997;640: 34-37.

4 Goldstein DS: Stress-induced activation of the sympathetic nervous system. Baillieres Clin Endocrinol Metab 1987;1:253-278.

5 Bennett SA, Magnus P: Trends in cardiovascular risk factors in Australia. Med J Aust 1994;161:519-527.

6 Light KC, Dolan CA, Davis MR, Sherwood A: Cardiovascular responses to an active coping challenge as predictors of blood pressure patterns 10-15 years later. Psychosom Med 1992;54:217-230.

7 Matthews KA, Woodall KL, Allen MT: Cardiovascular reactivity to stress predicts future blood pressure status. Hypertension 1993;22:479-485.

-8 Stewart JC, France CR: Cardiovascular recovery from stress predicts longitudinal changes in blood pressure. Biol Psychiatry 2001;58:105-120.

-9 Carroll D, Ring C, Hunt K, Ford G, Macintyre S: Blood pressure reactions to stress and prediction of future blood pressure: effects of sex, age, and socioeconomic position. Psychosom Med 2003;65:1058-1064.

10 Roth J, Qiang X, Marban SL, Redelt H, Lowell BC: The obesity pandemic: where have we been and where are we going? Obes Res 2004;12(suppl 2):88S-101S.

11 Waldstein SR, Burns HO, Toth MJ, Poehlman ET: Cardiovascular reactivity and central adiposity in older African Americans. Health Psychol 1999;18:221-228.

12 Barnes VA, Treiber FA, Davis H, Kelley TR, Strong WB: Central adiposity and hemodynamic functioning at rest and during stress in adolescents. Int J Obes Relat Metab Disord 1998;22:1079-1083.

13 Reims HM, Fossum E, Hoieggen A, Moan A, Eide I, Kjeldsen SE: Adrenal medullary overactivity in lean, borderline hypertensive young men. Am J Hypertens 2004;17:611-618.

14 Jern S, Bergbrant A, Bjorntorp P, Hansson L: Relation of central hemodynamics to obesity and body fat distribution. Hypertension 1992;19:520-527.

15 El-Wazir YM, Li S-G, Smith RG, Silcox DL, Brown DR, Randall DC: Parasympathetic response to acute stress is attenuated in young Zucker obese rats. Auton Neurosci 2008;143:33-39.

16 Benson S, Arck PC, Tan S, Mann K, Hahn S, Janssen OE, Schedlowski M, Elsenbruch S: Effects of obesity on neuroendocrine, cardiovascular, and immune cell responses to acute psychosocial stress in premenopausal women. Psychoneuroendocrinology 2009;34:181-189. 
Torres et al:: The Effect of Overweight/Obesity on Cardiovascular Responses to Acute Psychological Stress in Men Aged 50-70 Years

17 Pringle E, Phillips C, Thijs L, Davidson C, Staessen JA, de Leeuw PW, Jaaskivi M, Nachev C, Parati G, O’Brien ET, Tuomilehto J, Webster J, Bulpitt CJ, Fagard RH; Syst-Eur investigators: Systolic blood pressure variability as a risk factor for stroke and cardiovascular mortality in the elderly hypertensive population. J Hypertens 2003; 21:2251-2257.

18 Hansen TW, Thijs L, Li Y, Boggia J, Kikuya M, Bjorklund-Bodegard K, Richart T, Ohkubo T, Jeppesen J, TorpPedersen C, Dolan E, Kuznetsova T, Stolarz-Skrzypek K, Tikhonoff V, Malyutina S, Casiglia E, Nikitin Y, Lind L, Sandoya E, Kawecka-Jaszcz K, Imai Y, Wang J, Ibsen H, O’Brien E, Staessen JA; International Database on Ambulatory Blood Pressure in Relation to Cardiovascular Outcomes Investigators: Prognostic value of reading-toreading blood pressure variability over 24 hours in 8938 subjects from 11 populations. Hypertension 2010; 55:1049-1057.

19 Mertens IL, Van Gaal LF: Overweight, obesity, and blood pressure: the effects of modest weight reduction. Obes Res 2000;8:270-278.

20 Li Z, Snieder H, Su S, Harshfield GA, Treiber FA, Wang X: A longitudinal study of blood pressure variability in African-American and European American youth. J Hypertens 2010;28:715-722.

21 Kirschbaum C, Kudielka BM, Gaab MS, Schommer NC, Hellhammer DH: Impact of gender, menstrual cycle phase, and oral contraceptives on the activity of the hypothalamus-pituitary-adrenal axis. Psychosom Med 1999;61:154-162.

22 Gibson RS: Principles of nutritional assessment, 2nd ed. New York, Oxford University Press, 2005.

-23 Guelen I, Westerhof BE, Van Der Sar GL, Van Montfrans GA, Kiemeneij F, Wesseling KH, Bos WJ: Finometer, finger pressure measurements with the possibility to reconstruct brachial pressure. Blood Press Monit 2003; 8:27-30.

24 Schutte AE, Huisman HW, Van Rooyen JM, Oosthuizen W, Jerling JC: Sensitivity of the finometer device in detecting acute and medium-term changes in cardiovascular function. Blood Press Monit 2003;8:195-201.

25 Schutte AE, Huisman HW, van Rooyen JM, Malan NT, Schutte R: Validation of the finometer device for measurement of blood pressure in black women. J Hum Hypertens 2004;18:79-84.

-26 Wesseling KH, Jansen JR, Settels JJ, Schreuder JJ: Computation of aortic flow from pressure in humans using a nonlinear, three-element model. J Appl Physiol (1985) 1993;74:2566-2573.

27 Kirschbaum C, Pirke KM, Hellhammer DH: The 'Trier Social Stress Test' - a tool for investigating psychobiological stress responses in a laboratory setting. Neuropsychobiology 1993;28:76-81.

28 Flegal KM, Kit BK, Orpana H, Graubard BI: Association of all-cause mortality with overweight and obesity using standard body mass index categories: a systematic review and meta-analysis. JAMA 2013;309:71-82.

29 National Health and Medical Research Council: Clinical Practice Guidelines for the Management of Overweight and Obesity in Adults. Canberra, NHMRC, 2003.

-30 Tilbrook AJ, Rivalland EA, Turner AI, Lambert GW, Clarke IJ: Responses of the hypothalamopituitary adrenal axis and the sympathoadrenal system to isolation/restraint stress in sheep of different adiposity. Neuroendocrinology 2008;87:193-205.

-31 Levin BE, Triscari J, Sullivan AC: Abnormal sympatho-adrenal function and plasma catecholamines in obese Zucker rats. Pharmacol Biochem Behav 1980;13:107-113.

-32 Steptoe A, Wardle J: Cardiovascular stress responsivity, body mass and abdominal adiposity. Int J Obes 2005; 29:1329-1337.

-33 Torres SJ, Nowson CA: Effect of a weight-loss program on mental stress-induced cardiovascular responses and recovery. Nutrition 2007;23:521-528.

-34 Steptoe A, Willemsen G, Kunz-Ebrecht SR, Owen N: Socioeconomic status and hemodynamic recovery from mental stress. Psychophysiology 2003;40:184-191.

-35 Steptoe A, Marmot M: Impaired cardiovascular recovery following stress predicts 3-year increases in blood pressure. J Hypertens 2005;23:529-536.

-36 Chobanian AV, Bakris GL, Black HR, Cushman WC, Green LA, Izzo JL Jr, Jones DW, Materson BJ, Oparil S, Wright JT Jr, Roccella EJ; National Heart, Lung, and Blood Institute Joint National Committee on Prevention, Detection, Evaluation, and Treatment of High Blood Pressure; National High Blood Pressure Education Program Coordinating Committee: The seventh report of the Joint National Committee on Prevention, Detection, Evaluation, and Treatment of High Blood Pressure: the JNC 7 report. JAMA 2003;289:2560-2572.

37 Weidmann P, de Courten M, Boehlen L, Shaw S: The pathogenesis of hypertension in obese subjects. Drugs 1993;46(suppl 2):197-208.

-38 Edgell H, Petrella RJ, Hodges GJ, Shoemaker JK: Central versus peripheral cardiovascular risk in metabolic syndrome. Front Physiol 2012;3:38-38.

-39 Kirschbaum C, Strasburger CJ, Langkrar J: Attenuated cortisol response to psychological stress but not to CRH or ergometry in young habitual smokers. Pharmacol Biochem Behav 1993;44:527-531.

40 Silke B, McAuley D: Accuracy and precision of blood pressure determination with the Finapres: an overview using re-sampling statistics. J Hum Hypertens 1998;12:403-409.

41 Imholz BP, Wieling W, van Montfrans GA, Wesseling KH: Fifteen years experience with finger arterial pressure monitoring: assessment of the technology. Cardiovasc Res 1998;38:605-616. 